\title{
PENDUGAAN PARAMETER REGRESI PANEL DINAMIS DENGAN BLUNDELL AND BOND GENERALIZED METHOD OF MOMENT
}

\author{
AZMI ARSA, YUDIANTRI ASDI, FERRA YANUAR \\ Program Studi Matematika, \\ Fakultas Matematika dan Ilmu Pengetahuan Alam, Universitas Andalas, \\ Kampus UNAND Limau Manis Padang, Indonesia, \\ email : azmiarsa@gmail.com
}

\begin{abstract}
Abstrak. Model regresi data panel dinamis merupakan model regresi data panel yang melibatkan lag dari peubah bebas sebagai peubah penjelas yang berkorelasi dengan error. Lag dari peubah bebas tersebut dinamakan peubah endogen penjelas. Adanya peubah endogen penjelas menyebabkan pendugaan parameter dengan metode kuadrat terkecil menghasilkan dugaan yang bias dan tidak konsisten.
\end{abstract}

\section{PENDAHULUAN}

Data panel merupakan gabungan dari data runtun waktu (time series) dengan data silang (cross section), dimana pengamatan dari sejumlah individu dikumpulkan menurut runtun waktu tertentu. Data panel biasanya digunakan dalam mengatasi permasalahan perekonomian. Hubungan yang digunakan peubah-peubah dalam model perekonomian biasanya bersifat dinamis. Analisis data panel yang lebih sesuai untuk menggambarkan kedinamisan ini adalah regresi data panel dinamis.

Pada model regresi panel dinamis terdapat korelasi antara lag peubah respon dengan galat. Hal ini menyebabkan pendugaan parameter dengan metode OLS dan GLS akan menghasilkan dugaan parameter yang bias dan tidak konsisten. Untuk mengtasi hal tersebut, Blundell dan Bond mengajukan metode BB-GMM sebagai metode pendugaan parameter regresi panel dinamis.

\section{LANDASAN TEORI}

\subsection{Regresi Data Panel}

Data panel adalah gabungan antara data silang dan data runtun waktu, dimana data silang yang sama diukur pada waktu yang berbeda. Pada data panel, data yang sama diukur selama beberapa periode waktu. Jadi dapat dikatakan data panel memiliki dimensi ruang dan waktu.

Secara umum model regresi panel dinyatakan sebagai berikut :

$$
y_{i t}=\alpha_{i t}+\beta^{\prime} \mathbf{X}_{\mathbf{i t}}+u_{i t}
$$


dimana

$$
\begin{aligned}
y_{i t}: & \text { unit data silang ke-i untuk periode waktu ke-t. } \\
\beta^{\prime}=\left(\beta_{1}, \beta_{2}, \cdots, \beta_{k}\right): & \text { vektor konstanta berukuran } 1 \times k \\
& \text { dengan } k \text { banyaknya peubah bebas. } \\
\mathbf{X}_{\mathbf{i t}}=\left(X_{1}{ }_{i t}, X_{2} i t, \cdots, X_{k i t}\right): & \text { vektor observasi pada peubah bebas berukuran } 1 \times k . \\
\alpha_{i t}: & \text { intersep merupakan efek grup atau individu unit data silang ke-i } \\
& \text { dan periode waktu ke }-t . \\
u_{i t}: & \text { komponen error dengan } \operatorname{IIDN}\left(0, \sigma^{2}\right), \\
& \text { dengan } i=1,2, \cdots ; t=1,2, \cdots .
\end{aligned}
$$

Berdasarkan komponen error, model regresi data panel terbagi dua, yaitu [5]:

(1) Model regresi data panel komponen error 1-arah:

$$
y_{i t}=\alpha_{i t}+\beta^{\prime} \mathbf{X}_{\mathbf{i t}}+u_{i t}, \text { dimana } u_{i t}=\mu_{i}+v_{i t}
$$

(2) Model regresi data panel komponen error 2-arah:

$$
y_{i t}=\alpha_{i t}+\beta^{\prime} \mathbf{X}_{\mathbf{i t}}+u_{i t} \text {, dengan } u_{i t}=\mu_{i}+\lambda_{t}+v_{i t},
$$

dimana:

$\mu_{i}$ : adalah pengaruh yang tidak terobservasi dari individu.

$\lambda_{t}$ : adalah pengaruh waktu yang tidak teramati.

$v_{i t}$ : adalah kesalahan pengganggu.

\subsubsection{Metode Instrumen Variabel [6]}

Metode instrument variabel merupakan metode yang digunakan untuk mengatasi masalah yang terjadi pada model regresi linier yang menghasilkan taksiran parameter yang bias dan tidak konsisten. Metode ini akan menghilangkan efek peubah bebas pada model, sehingga menghasilkan taksiran parameter yang tak bias dan konsisten.

Metode Instrumen Variabel (IV) memberikan solusi umum untuk masalah peubah bebas endogen. Untuk menggunakan pendekatan IV, kita membutuhkan peubah observasi $z_{1}$, yang memenuhi dua kondisi :

(1) $z_{1}$ tidak berkorelasi dengan $u$ :

$$
\operatorname{cov}\left(z_{1}, u\right)=0
$$

atau dengan kata lain, sama seperti $x_{1}, x_{2}, \cdots, x_{k-1}, z_{1}$ adalah eksogen.

(2) $z_{1}$ berkorelasi dengan $x_{k}$

Diperlukan proyeksi linier dari $x_{k}$ pada semua peubah eksogen:

$$
x_{k}=\delta_{0}+\delta_{1} x_{1}+\delta_{2} x_{2}+\cdots+\delta_{k-1} x_{k-1}+\theta_{1} z_{1}+r_{k}
$$

Terdapat dua kasus yang dapat terjadi untuk mengestimasi parameter pada persamaan (2.1) yaitu: 
(1) Peubah endogen $x_{k}$ pada persamaan (2.1) di instrumen hanya oleh satu variabel instrumen yaitu $z_{1}$.

(2) Peubah endogen $x_{k}$ pada persamaan (2.1) di instrumen oleh banyak variabel instrumen, misalkan variabel instrumen tersebut $z_{1}, z_{2},, z_{m}$.

Penduga parameter dengan metode instrument variabel dapat dinyatakan sebagai berikut.

$$
\beta=\left[E\left(\mathbf{x}^{\prime} \mathbf{z}\right)\right]\left[E\left(\mathbf{z}^{\prime} \mathbf{z}\right)\right]^{-1} E\left(\mathbf{x}^{\prime} \mathbf{z}\right)\left[E\left(\mathbf{z}^{\prime} \mathbf{z}\right)\right]^{-1} E\left(\mathbf{z}^{\prime} y\right) .
$$

\subsubsection{Generalized Method of Moment (GMM) [6]}

GMM adalah perluasan dari metode momen, dimana metode momen merupakan salah satu metode yang dapat digunakan untuk mencari penaksir yang konsisten dari suatu parameter. Dalam metode momen banyaknya variabel instrument harus sama dengan jumlah parameter yang akan ditaksir. Untuk kasus dimana banyaknya variabel instrumen lebih banyak dari jumlah parameter yang akan ditaksir, maka metode momen tidak bisa digunakan lagi. Oleh karena itu digunakan Generalized Methode of Moment (GMM).

Ide dasar $G M M$ adalah meminimumkan penduga untuk $\beta$ sehingga $g(\hat{\beta}=0$. Misalkan L merupakan jumlah variabel instrument dan K adalah jumlah parameter yang akan ditaksir,

(1) Jika $L=K$ maka $G M M$ adalah penduga metode momen itu sendiri dengan parameter $\hat{\beta}$ adalah sebagai berikut,

$$
\hat{\beta}=\left(N^{-1} \sum_{i=1}^{n} \mathbf{z}^{\prime} \mathbf{x}_{\mathbf{i}}\right)\left(N^{-1} \sum_{i=1}^{n} \mathbf{z}^{\prime} y_{i}\right)
$$

(2) Jika $L>K$ artinya jumlah variabel instrumen lebih banyak dari parameter yang akan ditaksir sehingga metode momen tidak bisa digunakan lagi. Oleh karena itu untuk mengatasinya digunakan generalized method of moment $(G M M)$. Ide dasarnya dalah meminimumkan matriks terboboti dari momen kondisi sampel. Misalkan matriks terboboti tersebut adalah $\hat{W}$.

$$
\|\bar{g}(\beta)\|_{\hat{W}}^{2}=\bar{g}(\hat{\beta})^{\prime} \hat{\mathbf{W}} g(\hat{\beta})
$$

\section{PEMBAHASAN}

\subsection{Pendugaan Parameter dengan metode Blundell dan Bond}

Penaksiran parameter yang dilakukan oleh Blundell dan Bond merupakan lanjutan dari penelitian yang dilakukan oleh Arellano dan Bond. Sebenarnya taksiran parameter yang dilakukan oleh Arellano dan Bond sudah tak bias, efisien dan konsisten. Namun Blundell dan Bond mengajukan suatu metode yang baru yang diklaim lebih efisien dan konsisten. Blundell dan Bond melakukan penambahan informasi momen kondisi dan matriks instrumen variabel. Hal ini dilakukan dengan mengkombinasikan matriks model pembedaan dan model deret asli. 
Definisikan matriks variabel instrumen untuk model deret asli sebagai berikut:

$$
\mathbf{z}_{\mathbf{u m}}=\left[\begin{array}{cccc}
{\left[\Delta y_{i, 2}, x_{i, 3}\right]} & 0 & \cdots & 0 \\
0 & {\left[\Delta y_{i, 2}, \Delta y_{i, 3}, x_{1,4}\right]} & \cdots & 0 \\
\vdots & \vdots & \ddots & \vdots \\
0 & 0 & \cdots & {\left[\Delta y_{i, 2}, \Delta y_{i, 3}, \cdots \Delta y_{i, T-1}, x_{i, T}\right]}
\end{array}\right]
$$

Karena $z_{u m}$ berisikan variabel-variabel instrumen, maka asumsi yang dibutuhkan dalam pendugaan adalah:

$$
\begin{aligned}
E\left(\mathbf{z}_{\mathbf{u m}}{ }^{\prime} u_{i}\right) & =\mathbf{0}, \\
\operatorname{rank} E\left(\mathbf{z}_{\mathbf{u m}}{ }^{\prime} y_{i-1}\right) & =1 .
\end{aligned}
$$

Selanjutnya akan dicari penduga $\beta$ dengan mengkombinasikan model pembedaan dengan model deret asli. Definisikan model deret asli sebagai berikut:

$$
y_{i t}=\delta y_{i, t-1}+\beta^{\prime} \mathbf{X}_{\mathbf{i t}}+u_{i t}
$$

Model pembedaan dalam bentuk matriks:

$$
\delta \mathbf{y}_{\mathbf{i}, \mathbf{t}}=\delta \boldsymbol{\Delta} \mathbf{y}_{\mathbf{i}, \mathbf{t}-\mathbf{1}}+\beta \boldsymbol{\Delta} \mathbf{x}_{\mathbf{i}, \mathbf{t}}+\boldsymbol{\Delta} \mathbf{v}_{\mathbf{i}, \mathbf{t}} .
$$

Model deret asli dalam bentuk matriks:

$$
\mathbf{y}_{\mathbf{i}, \mathbf{t}}=\delta \mathbf{y}_{\mathbf{i}, \mathbf{t}-\mathbf{1}}+\beta^{\prime} \mathbf{X}_{\mathbf{i}, \mathbf{t}}+\mathbf{u}_{\mathbf{i}, \mathbf{t}}
$$

Sehingga kombinasi modelnya adalah sebagai berikut:

$$
\left(\begin{array}{c}
\Delta y \\
y
\end{array}\right)=\beta\left(\begin{array}{c}
\Delta x \\
x
\end{array}\right)+\left(\begin{array}{c}
\Delta v \\
v
\end{array}\right) .
$$

Berdasarkan kombinasi tersebut matriks instrumen variabel gabungan dapat didefinisikan sebagai berikut:

$$
\mathbf{z}_{\mathbf{s i s}}=\left[\begin{array}{cc}
\mathbf{z}_{\mathbf{d i f}} & 0 \\
0 & \mathbf{z}_{\mathbf{u m}}^{\mathbf{p}}
\end{array}\right]=\left[\begin{array}{ccccc}
\mathbf{z}_{\mathbf{d i f}} & 0 & 0 & \cdots & 0 \\
0 & \Delta y_{i, 2}, x_{i, 3} & 0 & \cdots & 0 \\
0 & 0 & \Delta y_{i, 3}, x_{i, 4} & \cdots & 0 \\
\vdots & \vdots & \vdots & \vdots & \vdots \\
0 & 0 & 0 & \cdots & \Delta y_{i, T-1}, x_{i, T}
\end{array}\right]
$$

dimana $\mathbf{z}_{\mathbf{u m}}^{\mathbf{p}}$ merupakan non-redundant subset dari $z_{u m}, z_{\text {dif }}$ merupakan matriks variabel pembedaan yang ditemukan oleh Arellano dan Bond dan $z_{\text {sis }}$ merupakan matriks berukuran $(2 T-4) x\left(\frac{1}{2}(T-2)(T+5)\right)$. Kita definisikan $z_{\text {dif }}$ sebagai berikut: $\mathbf{z}_{\text {dif }}=\left[\begin{array}{cccc}{\left[y_{i, 2}, \Delta x_{i, 3}\right]} & 0 & \cdots & 0 \\ 0 & {\left[y_{i, 2}, y_{i, 3}, \Delta x_{i, 4}\right]} & \cdots & 0 \\ \vdots & \vdots & \ddots & \vdots \\ 0 & 0 & \cdots & {\left[y_{i, 2}, y_{i, 3}, \cdots y_{i, T-1}, \Delta x_{i, T}\right]}\end{array}\right]$ 


\subsubsection{One Step Consistent Estimator}

One Step Consistent Estimator merupakan metode pendugaan parameter yang dilakukan oleh Blundell dan Bond untuk mendapatkan parameter yang konsisten. Dibawah asumsi (3.1), vektor $\widehat{\beta}$ merupakan solusi tunggal untuk momen kondisi populasi [6]

$$
\hat{\beta}=\left[\left[N^{-1} \sum_{i=1}^{n} \theta^{\prime} \mathbf{z}_{\mathbf{s i s}}\right] \boldsymbol{\Lambda}^{-\mathbf{1}}\left[N^{-1} \sum_{i=1}^{n} \mathbf{x}_{\mathbf{s i s}}^{\prime} \theta\right]\right]^{\prime}\left[\left[N^{-1} \sum_{i=1}^{n} \theta^{\prime} \mathbf{z}_{\mathbf{s i s}}\right] \boldsymbol{\Lambda}^{-\mathbf{1}}\left[N^{-1} \sum_{i=1}^{n} \mathbf{x}_{\mathbf{s i s}}^{\prime} \varphi\right]\right]^{\prime} .
$$

\section{Kesimpulan}

Pada tulisan ini telah dibuktikan bahwa penduga yang dihasilkan dari metode one step consistence estimator adalah penduga yang konsisten untuk sebarang matriks pembobot $\hat{\mathbf{W}}$. Namun, apabila kita memilih matriks pembobot $\hat{\mathbf{W}}$ yang meminimumkan asymptotic variance dari $\hat{\beta}$, maka akan dihasilkan penduga yang efisien $[6]$.

$$
\hat{\beta}=\left[\left[N^{-1} \sum_{i=1}^{n} \theta^{\prime} \mathbf{z}_{\mathbf{s i s}}\right] \boldsymbol{\Lambda}^{-\mathbf{1}}\left[N^{-1} \sum_{i=1}^{n} \mathbf{x}_{\mathbf{s i s}}^{\prime} \theta\right]\right]^{\prime}\left[\left[N^{-1} \sum_{i=1}^{n} \theta^{\prime} \mathbf{z}_{\mathbf{s i s}}\right] \boldsymbol{\Lambda}^{-\mathbf{1}}\left[N^{-1} \sum_{i=1}^{n} \mathbf{x}_{\mathbf{s i s}}^{\prime} \varphi\right]\right]^{\prime} .
$$

\section{Daftar Pustaka}

[1] A. Howard, C. Rorres. 2004. Aljabar Linier Elementer Versi Aplikasi. Edisi kedelapan jilid 1. Erlangga, Jakarta.

[2] Bain, L.J. 1992. Introduction To Probability and Mathematical Statistic. Second Edition. Kent Publishing Company, PWS.

[3] E. Hansen, Bruce. 2000. Econometric. Department of Economics, University of Winconsin.

[4] Greenee, H.W. 2012. Econometric Analysis. Prentice Hall International, United State of America.

[5] H. Baltigi, Badi. 2005. Econometric Analysis of Panel Data. John Wiley and Sons, United State of America.

[6] M. Wooldrige, Jefrey. 1993. Econometric Analysis of Cross Section and Panel Data. The MIT Press, London.

[7] Supranto, J. 2000. Statistik Teori dan Aplikasi. Edisi Keenam Jilid 1. Erlangga, Jakarta. 